\title{
ORIGINAL ARTICLE \\ Serum 25(OH)D, PTH and correlates of suboptimal 25(OH)D levels in persons with chronic spinal cord injury
}

\author{
K Hummel $^{1}$, BC Craven ${ }^{2,3}$ and L Giangregorio ${ }^{1,2}$
}

\begin{abstract}
Study design: Cross-sectional cohort study.
Objectives: To describe: (1) the prevalence of suboptimal 25-hydroxyvitamin D status (serum $25(\mathrm{OH}) \mathrm{D}<75 \mathrm{nmol} \mathrm{I}^{-1}$ ) and to identify correlates of vitamin D deficiency; (2) the prevalence of secondary hyperparathyroidism (serum intact parathyroid hormone $\left.(\mathrm{PTH}) \geqslant 7.0 \mathrm{pmol} \mathrm{I}^{-1}\right)$; and $(3)$ the relationships between serum PTH and $25(\mathrm{OH}) \mathrm{D}$ in adult men and women with chronic spinal cord injury $(\mathrm{SCl})$.
\end{abstract}

Setting: Outpatient services, including an osteoporosis clinic at a tertiary spinal cord rehabilitation hospital in Ontario.

Methods: Serum levels of 25(OH)D and intact PTH were acquired at enrollment. Clinical correlates of suboptimal vitamin D status were collected via interview and chart abstraction, and identified by univariate logistic regression analysis. Pearson correlations were run to assess the relationships between serum PTH and 25(OH)D. Significance was $P<0.05$.

Results: Thirty-nine percent of the cohort, comprised of 62 adult men and women with chronic SCI, had suboptimal serum 25(OH)D levels. Factors associated with suboptimal vitamin $D$ levels included having vitamin $D$ assessed in the winter months (odds ratio $(O R)=7.38, P=0.001)$, lack of a calcium supplement $(\mathrm{OR}=7.19, P=0.003)$, lack of a vitamin $D$ supplement $(O R=7.41$, $P=0.019)$, younger age $(\mathrm{OR}=0.932, P=0.010)$, paraplegia $(\mathrm{OR}=4.22, P=0.016)$, and lack of bisphosphonate $(\mathrm{OR}=3.85$, $P=0.015)$. Significant associations were observed between serum PTH and 25(OH)D $(r=-0.304, P=0.032)$ and between PTH and C-telopeptide of type I collagen (CTX-I) $(r=0.308, P=0.025)$.

Conclusions: Disruption of the vitamin D-PTH axis may contribute to the bone loss seen in the chronic SCl population. The threshold for optimal serum 25(OH)D levels in the chronic SCl population may be higher than in the non-SCl population. Serum 25(OH)D level are likely important risk factors contributing to declining bone mass and increased fracture risk post-SCI.

Spinal Cord (2012) 50, 812-816; doi:10.1038/sc.2012.67; published online 19 June 2012

Keywords: Vitamin D; PTH; osteoporosis; spinal cord injury

\section{INTRODUCTION}

Osteoporosis is a disease characterized by low bone mass, compromised bone structure, and an increased fracture risk. ${ }^{1}$ Sublesional osteoporosis is a disease process unique to persons with spinal cord injury (SCI), and is associated with regional declines in hip and knee region bone mass, alterations in bone structure and an increased propensity for fragility fracture of the distal femur, proximal tibia and hip regions. ${ }^{2}$ The prevalence of sublesional osteoporosis in the SCI population is estimated to be as high as $82 \%,{ }^{3,4}$ with fracture occurrence double that of the non-SCI population. ${ }^{5}$ Furthermore, $25-34 \%$ of individuals with SCI are reported to have sustained at least one lower extremity fracture since their SCI. ${ }^{4,6}$ Low trauma fractures in the SCI population occur during activities of daily living, and often require hospitalization, resulting in further immobility. ${ }^{7}$

Vitamin D deficiency and secondary hyperparathyroidism may contribute to the development of osteoporosis in SCI. ${ }^{8}$ The prevalence of vitamin D deficiency in the SCI population has been estimated as high as 93\%. ${ }^{9}$ Additionally, one-third of individuals with chronic SCI demonstrated serum 25-hydroxy vitamin D status (serum 25(OH)D) levels less than the normal range, and had associated secondary hyperparathyroidism, potentially contributing to accelerated bone resorption. ${ }^{10}$ Vitamin D deficiency and associated secondary hyperparathyroidism may represent a modifiable risk factor for fractures among individuals with SCI and sublesional osteoporosis.

Currently, there is no universal definition of an optimal serum $25(\mathrm{OH}) \mathrm{D}$ level for bone health. Serum $25(\mathrm{OH}) \mathrm{D}$ levels between 78 and $80 \mathrm{nmoll}^{-1}$ have been proposed for maximizing calcium absorption and suppressing parathyroid hormone (PTH), and it has been suggested that a minimum vitamin $\mathrm{D}$ intake of $1000 \mathrm{IU}$ per day is needed to achieve this. ${ }^{11}$ Data suggests that vitamin D intake is not sufficient among individuals with SCI; even in those who achieve an adequate intake. ${ }^{12}$ Bauman et al. ${ }^{10}$ demonstrated that after daily supplementation with $800 \mathrm{IU}$ of vitamin D for 12 months, 9 of 40 participants were still $25(\mathrm{OH}) \mathrm{D}$ deficient $\left(<40 \mathrm{nmoll}^{-1}\right)$, and only 8 participants reached levels greater than $75 \mathrm{nmoll}^{-1}$. It is unclear if the proposed guidelines for vitamin D sufficiency and intake for the general population ${ }^{13}$ are sufficiently high to adequately suppress $\mathrm{PTH}$ in the SCI population.

The primary purpose of this study was to identify the proportion of individuals with chronic SCI that have suboptimal vitamin D status (serum $25(\mathrm{OH}) \mathrm{D}<75 \mathrm{nmoll}^{-1}$ ) and the proportion that have secondary hyperparathyroidism (Intact $\mathrm{PTH} \geqslant 7.0 \mathrm{pmoll}^{-1}$ ). Additionally, we

${ }^{1}$ Department of Kinesiology, University of Waterloo, Waterloo, Ontario, Canada; ${ }^{2}$ Department of Research, Toronto Rehabilitation Institute- University Health Network, Toronto, Ontario, Canada and ${ }^{3}$ Department of Medicine, University of Toronto, Toronto, Ontario, Canada

Correspondence: K Hummel, Department of Kinesiology, University of Waterloo, 18 Harbour Street Unit 1009, Waterloo, Ontario, Canada M5J 2Z6.

E-mail: kayla.hummel@gmail.com

Received 5 January 2012; revised 17 April 2012; accepted 3 May 2012; published online 19 June 2012 
aimed to identify correlates of suboptimal vitamin D status in those with chronic SCI. Secondary goals were to evaluate the relationships between serum PTH and serum $25(\mathrm{OH}) \mathrm{D}$, as well as between serum PTH and serum ionized calcium and serum C-telopeptide of type I collagen (CTX-I), a marker of bone resorption.

\section{MATERIALS AND METHODS}

\section{Setting and study population}

The primary and secondary research questions were addressed using baseline data from two longitudinal studies being conducted by the University of Waterloo and the Toronto Rehabilitation Institute. Assessments were completed between April 2009 and December 2011. To ensure neurologic stability, only individuals who were $\geqslant 24$ months post injury were eligible to participate. To establish a representative sample of the SCI population, males and females with a spinal cord impairment (C1-L2 American Spinal Cord Injury Association Impairment Scale (AIS) A-D) of sudden onset, and either a motor complete (AIS A and B) or motor incomplete (AIS C and D) injury were recruited. Individuals were excluded from the study if they had current or prior conditions other than SCI known to influence bone metabolism. Participants were recruited primarily from: (a) the Jousse Long-term Follow-up Database; and (b) Outpatient services at Lyndhurst Centre. Baseline data from participants in an ongoing clinical trial $(n=10)$ at our center were included in the current analysis; however, these participants contributed vitamin D levels only.

\section{Outcome assessments}

Medical history and demographics. Questionnaires were completed via interview to record past and current medical health status, medication use, lifestyle and demographic data, fracture history and information related to the SCI. Medical history and impairment descriptors were also abstracted from the patient's medical record. A physiatrist (BC Craven) determined the participants' neurologic level of injury and AIS using the International Standards for the Neurologic Classification of SCI. ${ }^{14}$ Height, weight, waist circumference, calcium intake and supplement use were recorded.

Blood collection for serum analysis. Blood collection was performed by a trained phlebotomist. Participants fasted for at least $12 \mathrm{~h}$ before blood collection. Blood samples were drawn using a closed, sterile Vacutainer system (BD Vacutainer, Becton, Dickinson and Company, Franklin Lakes, NJ, USA). The collected samples were placed on ice and sent to the Research Laboratory at Mt. Sinai Hospital for immediate analysis.

Serum 25(OH)D was determined with a chemiluminescent immunoassay using the Diasorin LIAISON (Diasorin S.p.A., Vericelli, Italy); which exhibits $100 \%$ cross-reactivity for both $25(\mathrm{OH}) \mathrm{D}_{2}$ and $25(\mathrm{OH}) \mathrm{D}_{3}$ to estimate the total $25(\mathrm{OH}) \mathrm{D}$ circulating in the body. ${ }^{15}$

PTH was determined with an electrochemiluminescent immunoassay using the Roche Elecsys 1010/2010 and modular analytics E170 immonoassay analyzers (Roche Diagnostics, Mannheim, Germany).

Serum ionized calcium concentration was determined using potentiometers (ABL 735 Analyzer, Radiometer, Brønshøj, Denmark) to relate the electrical potential of the ionized calcium in the serum sample to its concentration using the Nernst equation. Serum CTX-I was measured with an electrochemiluminescent immunoassay on the Roche Elecsys 1010/2010 and modular analytics E170 immonoassay analyzer (Roche Diagnostics).

\section{Statistical analyses}

Participant characteristics, including serum 25(OH)D levels and PTH levels were summarized using descriptive statistics: mean (s.d.) for continuous variables and count (percent) for categorical variables. Vitamin D levels were categorized as suboptimal $\left(<75 \mathrm{nmoll}^{-1}\right)$ or optimal $\left(\geqslant 75 \mathrm{nmoll}^{-1}\right)$. Serum PTH was characterized as normal $\left(1.6-6.9 \mathrm{pmoll}^{-1}\right)$ or above the upper limit of the normal range $\left(\geqslant 7 \mathrm{pmoll}^{-1}\right)$. Univariate logistic regression analyses were performed to identify whether the following characteristics were associated with suboptimal vitamin D status: time of year, age, gender, injury level, injury completeness, duration of injury and supplement use. Additional characteristics assessed include: bisphosphonate use, and smoking status. Odds ratios (ORs), 95\% confidence intervals (CI), and $P$-values were reported.

Pearson correlation analyses were performed to evaluate the relationships between serum PTH and serum 25(OH)D, and between serum PTH and ionized calcium, as well as between serum PTH and CTX-I and between serum 25(OH)D and CTX-I. Correlation coefficients $(r)$ and $P$-values were reported for all correlation analyses. A value of $P<0.05$ was considered significant. All analyses were done with SAS version 9.1 (Cary, NC, USA).

We certify that all applicable institutional and governmental regulations concerning the ethical use of human volunteers were followed during the course of this research.

\section{RESULTS}

Recruitment and sample size

Sixty-five individuals were recruited to participate in the current study. Sixty-two 25(OH)D, 53 PTH, 55 ionized calcium and 53 CTX-I measurements were included in the final analyses. Reasons for missing data include; difficulties with blood draw during baseline visit, errors in processing at the analysis lab, vitamin D levels available only and participants declining the blood draw.

\section{Participant characteristics}

All participants acquired their SCI from a traumatic event, and were at least 2 years post injury. The cohort consisted of 51 male and 14 female participants, with a mean age of $49( \pm 12)$ years. At the time of assessment, $86 \%$ of participants were taking vitamin D supplements, and $75 \%$ of participants were taking calcium supplements (Table 1). The range of vitamin D supplement doses consumed was from $200 \mathrm{IU}$ to $5000 \mathrm{IU}$ per day, with two individuals reporting taking 50000 IU weekly at some point in the past year. Forty-one percent were taking at least $1000 \mathrm{IU}$ per day not including a multivitamin. If one assumes that a multivitamin contains $250 \mathrm{IU}$ or $400 \mathrm{IU}$ of vitamin $\mathrm{D}$, two additional individuals (or $45 \%$ of the sample) were taking at least $1000 \mathrm{IU}$ per day of vitamin D.

\section{Serum vitamin D, PTH, ionized calcium and CTX-I}

Sixty-one percent $(95 \% \mathrm{CI}, 49-73)$ of the population had serum $25(\mathrm{OH}) \mathrm{D}$ levels in the optimal range (Table 2). The mean (s.d.) serum $25(\mathrm{OH}) \mathrm{D}$ level and the $95 \% \mathrm{CI}$ within the suboptimal category was $52.9( \pm 15.8) \mathrm{nmoll}^{-1}(95 \% \mathrm{CI}, 46.2-59.6)$, whereas that in the optimal category was 107.9 ( \pm 31.7$)$ nmoll $^{-1}$ (95\% CI, 97.5-118.3). If we used $<50 \mathrm{nmoll}^{-1}$ as a cutoff, $10 \%$ of our sample would have vitamin $\mathrm{D}$ insufficiency.

Eighty-seven percent (95\% CI, 78-96) of the population demonstrated serum intact PTH levels within the normal range (Table 2). The mean (s.d.) serum intact PTH level within the normal hormonal range was $3.8( \pm 1.4) \mathrm{pmoll}^{-1}$ (95\% CI, 3.3-4.2), whereas the mean (s.d.) serum intact PTH level in the group with secondary hyperparathyroidism was $9.0( \pm 2.4)$ pmoll $^{-1}$ (95\% CI, 6.8-11.2). Additionally, the $25(\mathrm{OH}) \mathrm{D}$ level above which all individuals were classified as having normal PTH was around $95 \mathrm{nmoll}^{-1}$.

Three individuals $(6 \%)$ had both suboptimal vitamin D and elevated PTH. Only one of the seven individuals with elevated PTH was not taking $1000 \mathrm{mg}$ of calcium daily, and that person was taking $400 \mathrm{mg}$. That same individual was the only one who was not taking supplemental vitamin D; all others were taking $750 \mathrm{IU}$ or greater. The mean (s.d.) of serum ionized calcium for the whole cohort was 1.24 $( \pm 0.04) \mathrm{mmol} \mathrm{l}^{-1}$ (Table 2). The mean (s.d.) of serum CTX-I was $263.6( \pm 145.2) \mathrm{ngl}^{-1}$. 
Table 1 Participant characteristics/descriptors

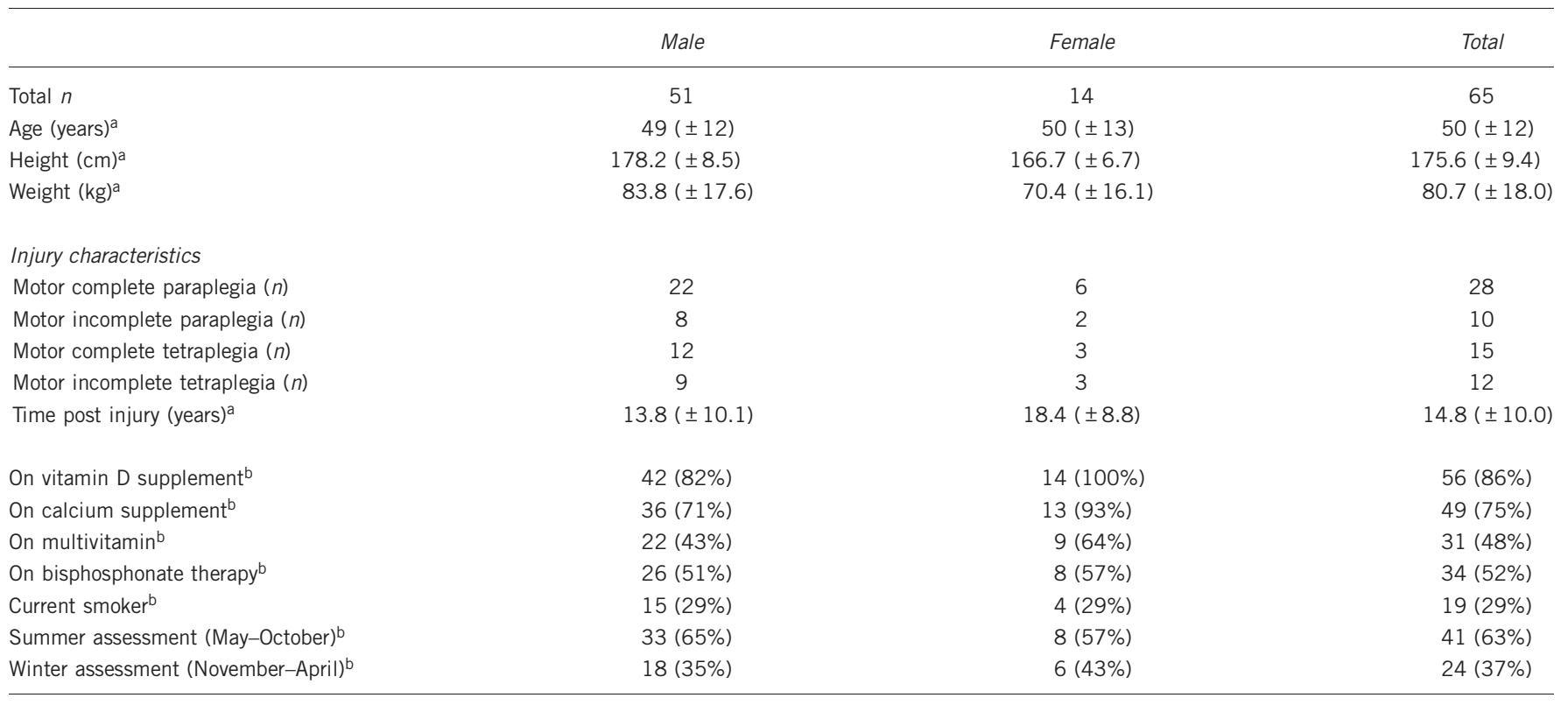

avalues are mean $( \pm$ s.d.)

balues are $n(\%)$.

Table 2 Serum results

\begin{tabular}{|c|c|c|c|c|c|}
\hline Serum measurement & $\mathrm{n}$ & Normal/optimal range & Mean ( \pm s.d.), $95 \% \mathrm{Cl}$ & Range & $\%$ in normal range, $95 \% \mathrm{Cl}$ \\
\hline Intact PTH (pmol I-1) & 53 & $1.6-6.9$ & $4.4( \pm 2.4), 3.8-5.1$ & $1.9-13.6$ & $87 \%, 78-96 \%$ \\
\hline CTX-I (ng |-1) & 53 & $\begin{array}{c}\text { Men: } 90-750 \\
\text { PreM. Women: } 50-900 \\
\text { PostM. Women: } 210-1100\end{array}$ & $263.6( \pm 145.2), 223.6-303.7$ & $45.0-701.0$ & $\begin{array}{c}\text { Men: } 95 \%, 88-100 \% \\
\text { PreM. W: } 100 \%, \text { N/A } \\
\text { PostM. W: } 50 \%, 10-90 \%\end{array}$ \\
\hline
\end{tabular}

Abbreviations: $\mathrm{Cl}$, confidence interval; CTX-I, C-telopeptide of type I collagen; PTH, parathyroid hormone; PreM., Pre-menopausal; PostM., Post-menopausal.

\section{Correlates of suboptimal vitamin D status}

Univariate logistic regression analyses were performed to identify population characteristics associated with vitamin D deficiency (Table 3). Those with vitamin D assessments performed in the winter months $(\mathrm{OR}=7.38, \mathrm{CI}=2.30-23.65, P=0.001)$, and those not taking vitamin $\mathrm{D}(\mathrm{OR}=7.41, \mathrm{CI}=1.39-39.53, P=0.019)$ or calcium $(\mathrm{OR}=7.19, \quad \mathrm{CI}=1.94-26.68, \quad P=0.003) \quad$ supplements had an increased odds of being vitamin $\mathrm{D}$ deficient. Additionally, younger age $(\mathrm{OR}=0.932, \mathrm{CI}=0.88-0.98, P=0.010)$, not being on bisphosphonate therapy $(\mathrm{OR}=3.85, \mathrm{CI}=1.30-11.34, P=0.015)$ and having paraplegia (versus tetraplegia) $(\mathrm{OR}=4.22, \quad \mathrm{CI}=1.31-13.65$, $P=0.016)$ were associated with vitamin D deficiency.

\section{Relationship between PTH and 25(OH)D and calcium}

There was a significant correlation between serum intact PTH and serum 25(OH)D levels $(r=-0.304, P=0.032)$ (Figure 1). Additionally, there was a significant positive correlation between serum CTX-I and serum intact PTH $(r=0.308, P=0.025)$ (Figure 2).

\section{DISCUSSION}

Although a large proportion of our sample reported vitamin D and multivitamin use, $39 \%$ of the study population with chronic SCI
Table 3 ORs of characteristics associated vitamin D deficiency $(n=62)$

\begin{tabular}{llll}
\hline Characteristic & OR & \multicolumn{1}{c}{$95 \% \mathrm{Cl}$} & P-value \\
\hline Winter months (November-April) & 7.38 & $2.30-23.65$ & $0.001^{\mathrm{a}}$ \\
Female & 0.460 & $0.11-1.91$ & 0.285 \\
Age & 0.932 & $0.88-0.98$ & $0.010^{\mathrm{a}}$ \\
Time post injury & 0.962 & $0.91-1.02$ & 0.170 \\
Motor complete injury & 0.679 & $0.23-2.01$ & 0.484 \\
Paraplegic & 4.22 & $1.31-13.65$ & $0.016^{\mathrm{a}}$ \\
Not on a vitamin D supplement & 7.41 & $1.39-39.53$ & $0.019^{\mathrm{a}}$ \\
Not on a calcium supplement & 7.19 & $1.94-26.68$ & $0.003^{\mathrm{a}}$ \\
Not on a multivitamin & 0.982 & $0.35-2.77$ & 0.973 \\
Not on bisphosphonate therapy & 3.85 & $1.30-11.34$ & $0.015^{\mathrm{a}}$ \\
Current smoker & 2.68 & $0.87-8.25$ & 0.086 \\
\hline
\end{tabular}

Abbreviations: $\mathrm{Cl}$, confidence interval; OR, odds ratio. asignificant $(P<0.05)$.

presented with serum $25(\mathrm{OH}) \mathrm{D}$ levels in the suboptimal range $\left(<75 \mathrm{nmoll}^{-1}\right)$, and $13 \%$ had secondary hyperparathyroidism. Additionally, having $25(\mathrm{OH}) \mathrm{D}$ assessed in the winter months, lack of a calcium or vitamin D supplement use, younger age, lack of 


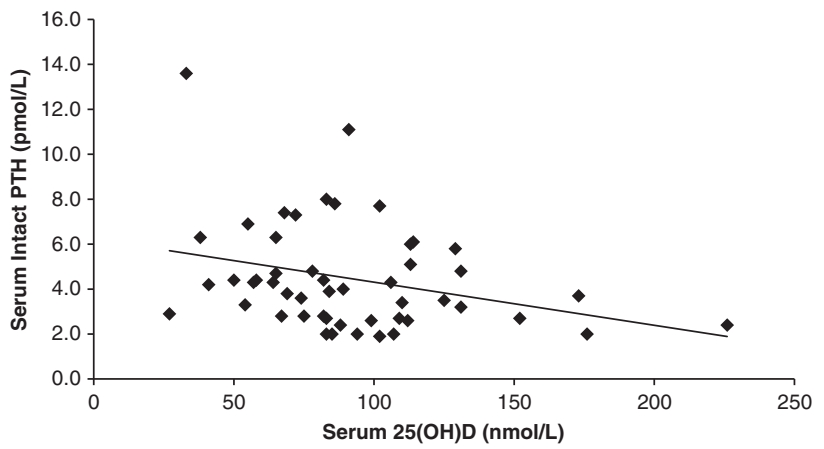

Figure 1 Association between serum intact PTH (pmoll ${ }^{-1}$ ) and 25(OH)D $\left.(\mathrm{nmoll})^{-1}\right)(r=-0.304, P=0.032)$.

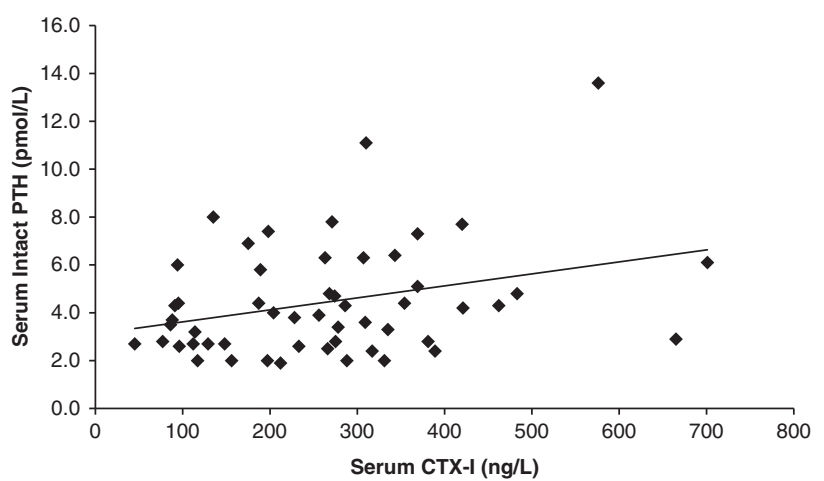

Figure 2 Correlation between serum intact PTH $\left(\mathrm{pmoll}^{-1}\right)$ and C-telopeptide $\left(\mathrm{ngl}^{-1}\right)(r=0.308, P=0.025)$.

bisphosphonate use and injury level were associated with suboptimal $25(\mathrm{OH}) \mathrm{D}$ serum levels. A novel finding of our work was that secondary hyperparathyroidism was associated with lower serum $25(\mathrm{OH}) \mathrm{D}$ and increased bone resorption (CTX-I), suggesting that disruption of the vitamin D-PTH axis may be a contributor to excess resorption and declining bone mass in the chronic SCI population.

Thirty-nine percent of the individuals with chronic SCI studied demonstrated suboptimal 25(OH)D levels $\left(<75 \mathrm{nmoll}^{-1}\right)$. One previous report of vitamin D status in the SCI population similarly identified more than $32 \%$ of participants with suboptimal serum $25(\mathrm{OH}) \mathrm{D}$ levels; ${ }^{10}$ however, deficiency was defined as $<40 \mathrm{nmoll}^{-1}$. Recently, Oleson et al. ${ }^{16}$ identified $96 \%$ of participants with chronic $\mathrm{SCI}$ as vitamin D deficient $\left(<80 \mathrm{nmoll}^{-1}\right)$. However, they excluded individuals consuming greater than $400 \mathrm{IU}$ of vitamin D per day, which may overestimate the prevalence of deficiency. Another study of vitamin D status in individuals with SCI, found 93\% to have inadequate $\left(<75 \mathrm{nmoll}^{-1}\right) 25(\mathrm{OH}) \mathrm{D}$ levels,${ }^{9}$ but this study was limited to an inpatient rehabilitation setting of acutely injured patients. We have reported the vitamin $\mathrm{D}$ status of men and women with chronic SCI residing in the community, with diverse impairments. Given many of the current study population were recruited from an osteoporosis clinic and were being monitored annually, the true prevalence of vitamin D deficiency in the SCI population may be closer to that in observed in the general population of post-menopausal women, which has been estimated as $64 \% .{ }^{17}$ Of the $39 \%$ found to have suboptimal serum $25(\mathrm{OH}) \mathrm{D}$ in the current study, $71 \%$ reported being on a vitamin D supplement, demonstrating that despite taking supplements, serum $25(\mathrm{OH}) \mathrm{D}$ concentrations are not reaching or not remaining at optimal levels over time. Therefore, serum 25(OH)D should be monitored over time after SCI, and the dosage of vitamin D prescribed titrated on an individual basis.

A novel observation in the current study was a significant positive relationship between serum CTX-I and serum intact PTH, identifying that higher PTH levels are associated with greater bone resorption, which is a modifiable risk factor for osteoporotic fracture in chronic SCI. The presence of secondary hyperparathyroidism may be associated with low vitamin D levels in chronic SCI. ${ }^{10}$ An inverse relationship between serum $25(\mathrm{OH}) \mathrm{D}$ and intact PTH has been demonstrated in older persons without $\mathrm{SCI},{ }^{18,19}$ and in individuals with long-standing SCI. ${ }^{10}$ Among older adults in a residential care setting, hyperparathyroidism in the presence of low vitamin D levels was associated with higher bone turnover and an increased risk of mortality; however, not all older adults with low vitamin D levels had a hyperparathyroid response, suggesting that some individuals may be more susceptible than others. ${ }^{20}$ Among our cohort $13 \%$ had serum PTH above the upper limit of normal, whereas 39\% had suboptimal vitamin D levels. The threshold of vitamin D needed in the general population to maximally suppress PTH release was shown to be as high as $80 \mathrm{nmoll}^{-1},{ }^{21}$ but it is not known if the threshold is different after SCI. Based on the current study, the data suggest that in those with chronic SCI, the serum 25(OH)D threshold for suppression of $\mathrm{PTH}$ is about $94 \mathrm{nmoll}^{-1}$. It would be interesting to evaluate the level of $25(\mathrm{OH}) \mathrm{D}$ at which the PTH plateaus in a larger sample of individuals with chronic SCI. Our work suggests that serial monitoring of vitamin D, PTH and CTX is necessary to prevent increased bone resorption among individuals with chronic SCI.

The following correlates of suboptimal vitamin D status in individuals with chronic SCI were identified in this study: youth, lack of a calcium or vitamin D supplement, assessment of vitamin D during the winter months, lack of bisphosphonate use and paraplegia. Our findings emphasize that many individuals with SCI are not acquiring enough vitamin $\mathrm{D}$ through sun exposure or diet. Opperman $^{22}$ reported vitamin D and calcium to be in the top-three supplements used in the SCI population, and given that vitamin D is often prescribed in conjunction with calcium, it is not surprising that lack of calcium supplementation is associated with vitamin D deficiency. Interestingly, being younger and having paraplegia (versus tetraplegia) were associated with an increased odds of suboptimal serum $25(\mathrm{OH}) \mathrm{D}$ levels. Vitamin $\mathrm{D}$ metabolism in younger individuals with SCI may be different to that of older individuals with SCI. Decreased renal function, medication use postSCI, and history of medication use may affect older and younger individuals differently. That younger age and paraplegia are associated with lower vitamin D status are unique findings, and others have observed the opposite, ${ }^{23}$ or that function and associated activity participation are more important correlates. There were 15 individuals aged 40 or younger in the current study. Therefore, we suggest that our findings be used for hypothesis-generating purposes in larger studies. Further, it is clear that vitamin D deficiency may be present despite the use of vitamin D supplements and therefore individuals using supplements should not be excluded from studies examining correlates of vitamin D deficiency or the relationship between PTH and bone turnover. The current results do help identify intervention targets for clinicians based on clinical history (for example, supplement use) and season of assessment. Routine monitoring of supplement adherence and titration of serum levels into the optimal range is required to optimize bone health, thereby minimizing or eliminating increases in PTH and maximizing absorption of calcium, magnesium and phosphate. 
Several study limitations should be acknowledged. We were unable to distinguish between newly occurring, recent or long-standing suboptimal vitamin D levels with the current study design. Additionally, other medications known to effect vitamin D metabolism, such as anticonvulsants, sex hormone levels, as well as sun exposure, and supplement adherence were not considered in the current analysis. Others have reported considerable seasonal variation in $25(\mathrm{OH}) \mathrm{D}$ levels among young people in the general population without SCI living in a similar catchment to those included in this study. ${ }^{24} \mathrm{We}$ attempted to account for sun exposure by looking at season as a risk factor. Many participants were recruited via physician referral from an outpatient osteoporosis clinic, thereby introducing recruitment bias. However, prevalence of suboptimal $25(\mathrm{OH}) \mathrm{D}$ in a non-SCI population has been shown to be independent of whether or not persons were on prescription osteoporosis treatment. ${ }^{25}$ The average age of our participants was 50 years, therefore typical 'young people' with SCI are under-represented. Although there are some factors affecting the external validity, there is no other literature evaluating vitamin D status in a similarly well-represented cohort (gender and impairment strata) of individuals with chronic SCI. Future studies should include strategies for accurately reflecting fluctuations in $25(\mathrm{OH}) \mathrm{D}$ levels over time in the study design and analysis.

\section{CONCLUSIONS}

Disruption of the vitamin D-PTH axis is likely an important contributor to declines in hip and knee region bone mineral density observed in the chronic SCI population. The negative association between vitamin D levels $(25(\mathrm{OH}) \mathrm{D})$ and PTH has been described amply in the general population and has been reported previously in those with SCI, but the positive association between PTH and markers of bone turnover is a new, confirmatory finding. Monitoring of Serum 25(OH)D levels is crucial among persons with chronic SCI to maintain normal PTH levels and attenuate increased bone turnover. Thirty-nine percent of the population studied demonstrated suboptimal vitamin D levels, despite a large proportion taking vitamin D and calcium supplements. Identified risk factors for suboptimal vitamin D levels in the SCI population include: younger age, lack of a calcium or vitamin $\mathrm{D}$ supplement, testing during the winter months, lack of bisphosphonate use and paraplegia.

\section{DATA ARCHIVING}

There were no data to deposit.

\section{CONFLICT OF INTEREST}

The authors declare no conflict of interest.

\section{ACKNOWLEDGEMENTS}

This work was funded by the Ontario Neurotrauma Foundation, the Canadian Institutes for Health Research and the Spinal Cord Injury Solutions Network.
1 Canada O. Osteoporosis and Osteoarthritis. [Fact Sheet], Toronto, 2008 ; Available from http://www.osteoporosis.ca/index.php/ci_id/7037/la_id/1.htm. [updated March 2008; cited 26 October 2011].

2 Craven BC, Robertson LA, McGillivray CF, Adachi JD. Detection and treatment of sublesional osteoporosis among patients with chronic spinal cord injury. Top Spinal Cord Inj Rehabil 2009; 14: 1.

3 Shojaei H, Soroush MR, Modirian E. Spinal cord injury-induced osteoporosis in veterans. J Spinal Disord Tech 2006; 19: 114-117.

4 Lazo MG, Shirazi P, Sam M, Giobbie-Hurder A, Blacconiere MJ, Muppidi M. Osteoporosis and risk of fracture in men with spinal cord injury. Spinal Cord 2001; 39: 208-214.

5 Vestergaard P, Krogh K, Rejnmark L, Mosekilde L. Fracture rates and risk factors for fractures in patients with spinal cord injury. Spinal Cord 1998; 36: 790-796.

6 Eser P, Frotzler A, Zehnder Y, Denoth J. Fracture threshold in the femur and tibia of people with spinal cord injury as determined by peripheral quantitative computed tomography. Arch Phys Med Rehabil 2005; 86: 498-504.

7 Morse LR, Battaglino RA, Stolzmann KL, Hallett LD, Waddimba A, Gagnon D et al. Osteoporotic fractures and hospitalization risk in chronic spinal cord injury. Osteoporos Int 2009; 20: 385-392.

8 Jiang SD, Jiang LS, Dai LY. Mechanisms of osteoporosis in spinal cord injury. Clin Endocrinol (Oxf) 2006; 65: 555-565.

9 Nemunaitis GA, Mejia M, Nagy JA, Johnson T, Chae J, Roach MJ. A descriptive study on vitamin $D$ levels in individuals with spinal cord injury in an acute inpatient rehabilitation setting. PM R 2010; 2: 202-208; quiz 28.

10 Bauman WA, Zhong YG, Schwartz E. Vitamin D deficiency in veterans with chronic spinal cord injury. Metabolism 1995; 44: 1612-1616.

11 Dawson-Hughes B, Heaney RP, Holick MF, Lips P, Meunier PJ, Vieth R. Estimates of optimal vitamin D status. Osteoporos Int 2005; 16: 713-716.

12 Bauman WA, Morrison NG, Spungen AM. Vitamin D replacement therapy in persons with spinal cord injury. J Spinal Cord Med 2005; 28: 203-207.

13 Vieth R. Why the minimum desirable serm 25-hydroxyvitamin $D$ level should be $75 \mathrm{nmol} / \mathrm{l}(30 \mathrm{ng} / \mathrm{ml})$. Best Pract Res Clin Endocrinol Metab 2011; 25: 681-691.

14 Maynard Jr FM, Bracken MB, Creasey G, Ditunno Jr JF, Donovan WH, Ducker TB et al. International standards for neurological and functional classification of spinal cord injury. american spinal injury association. Spinal Cord 1997; 35: 266-274.

15 Ersfeld DL, Rao DS, Body JJ, Sackrison Jr JL, Miller AB, Parikh N et al. Analytical and clinical validation of the $25 \mathrm{OH}$ vitamin D assay for the LIAIS ON automated analyzer. Clin Biochem 2004; 37: 867-874.

16 Oleson CV, Patel PH, Wuermser LA. Influence of season, ethnicity, and chronicity on vitamin D deficiency in traumatic spinal cord injury. J Spinal Cord Med 2010; 33 202-213.

17 Rizzoli R, Eisman JA, Norquist J, Ljunggren O, Krishnarajah G, Lim SK et al. Risk factors for vitamin $D$ inadequacy among women with osteoporosis: an international epidemiological study. Int J Clin Pract 2006; 60: 1013-1019.

18 Kuchuk NO, Pluijm SM, van Schoor NM, Looman CW, Smit JH, Lips P. Relationships of serum 25-hydroxyvitamin $D$ to bone mineral density and serum parathyroid hormone and markers of bone turnover in older persons. J Clin Endocrinol Metab 2009; 94 1244-1250.

19 Garnero P, Munoz F, Sornay-Rendu E, Delmas PD. Associations of vitamin D status with bone mineral density, bone turnover, bone loss and fracture risk in healthy postmenopausal women. The OFELY study. Bone 2007; 40: 716-722.

20 Chen JS, Sambrook PN, March L, Cameron ID, Cumming RG, Simpson JM et al. Hypovitaminosis $D$ and parathyroid hormone response in the elderly: effects on bone turnover and mortality. Clin Endocrinol (Oxf) 2008; 68: 290-298.

21 Chapuy MC, Preziosi P, Maamer M, Arnaud S, Galan P, Hercberg S et al. Prevalence of vitamin D insufficiency in an adult normal population. Osteoporos Int 1997; 7. 439-443.

22 Opperman EA, Buchholz AC, Darlington GA, Martin Ginis KA. Dietary supplement use in the spinal cord injury population. Spinal Cord 2010; 48: 60-64.

23 Vaziri ND, Pandian MR, Segal JL, Winer RL, Eltorai I, Brunnemann S. Vitamin D, parathormone, and calcitonin profiles in persons with long-standing spinal cord injury. Arch Phys Med Rehabil 1994; 75: 766-769.

24 Gozdzik A, Barta JL, Weir A, Cole DEC, Vieth R, Whiting S et al. Serum 25 Hydroxyvitamin D concentrations fluctuate seasonally in young adults of diverse ancestry living in toronto. American J Nutr 2010; 140: 2213-2220.

25 Lips P, Hosking D, Lippuner K, Norquist JM, Wehren L, Maalouf G et al. The prevalence of vitamin $D$ inadequacy amongst women with osteoporosis: an international epidemiological investigation. J Intern Med 2006; 260: 245-254. 